\begin{tabular}{ccc} 
& & Journal of Stroke Research \\
\hdashline & (JSR)
\end{tabular}

\title{
Anxiety disorders and homeopathy
}

\section{Balaji Deekshitulu P V}

Psychologist \& Alternative Medicine (Homeopathy) Practitioner, Sri Balaji Clinic, Tirupati, A.P, India

\begin{abstract}
The review article states that homeopathic remedies have been used throughout the world for thousands of years and their benefits have been repeatedly documented by physiological and psychological problems. Homeopathic medicines can formulate a positive change in people suffering from these distressing states of mind and behaviour it is proved can help the reducing their anxiety levels and thus capable of dealing with stressful situations this remedies work towards balancing the excitatory neurotransmitter levels in the brain.

How to cite this article:

Balaji Deekshitulu P V. Anxiety dis-

Keywords: orders and homeopathy. Journal of

Anxiety, Anxiety disorders, Homeopathy remedies.

\section{eSciencePublisher}

eSciPub LLC, Houston, TX USA.

Website: http://escipub.com/
\end{abstract}




\section{Introduction}

The word anxiety is derived from the Latin "anxietas" (to choke, throttle, trouble, and upset) and encompasses behavioral, affective and cognitive responses to the perception of danger. Anxiety is a normal human emotion. In moderation, anxiety stimulates an anticipatory and adaptive response to challenging or stressful events. In excess, anxiety destabilizes the individual and dysfunctional state results.

Anxiety is considered excessive or pathological when it arises in the absence of challenge or stress, when it is out of proportion to the challenge or stress in duration or severity, when it results in significant distress, and when it results in psychological, social, occupational, biological, and other impairment.

Anxiety is a psychological and physiological state characterized by somatic, emotional, cognitive, and behavioral components. The root meaning of the word anxiety is 'to vex or trouble'; in either the absence or presence of psychological stress, anxiety can create feelings of fear, worry, uneasiness and dread. Anxiety is considered to be a normal reaction to a stressor. It may help a person to deal with a difficult situation by prompting one to cope with it. When anxiety becomes excessive, it may fall under the classification of an Anxiety disorders.

\section{Anxiety Disorders :}

Neurotic disorders are basically related to stress, reaction to stress (usually maladaptive) and individual proneness to anxiety. Interestingly, both stress and coping have close association with socio-cultural factors. Culture can affect symptom presentation, explanation of the illness and help-seeking. Importance given to the symptoms and meaning assigned by the physician according to their cultural background also differ across culture. In this way culture can affect epidemiology, phenomenology as well as treatment outcome of psychiatric illness especially anxiety disorders. In this review an attempt has been made to highlight on any such difference if there, as well as this review will also reflect the important areas, in which Indian studies are lacking.
Differential diagnosis:

1) Obsessive compulsive personality.

2) Depressive disorders.

3) Phobic disorders.

4) Generalised anxiety disorders.

5) Post-traumatic stress disorders.

6) Tic disorders.

7) Anorexia nervosa.

Obsessive Compulsive Disorder or OCD is an anxiety disorder \& characterised by obsessive thoughts which are recurrent, unwanted \& usually anxiety-provoking, \& by compulsions, repeated acts which relieve feelings of tension. OCD is widely accepted to result from genetic vulnerability \&/or chemical changes in some area of brain.

Pathology: The precise pathology is not completely understood. According to psychological school - obsessions are considered anxiogenic. OCD patients cannot escape this anxiety \& therefore develop compulsion in an attempt to reduce or prevent the feared consequences. Reduction of anxiety reinforces the compulsive behaviour.

\section{ROLE OF HOMEOPATHY:}

Homeopathy as a science is Holistic in its approach.. Anxiety disorders cover a wide range of disorders from panic disorders to Agoraphobia to OCD. There are subjective symptoms like fear, palpitations and objective symptoms like increased sweating, tachycardia etc. Taking into account these symptoms homeopathy can offer excellent treatment in such patients.

The aptitude to reinforce mental calmness promotes wellness, liveliness and longevity. Homeopathic remedies work towards balancing the excitatory neurotransmitter levels in the brain. Homeopathic constitutional treatment will help eliminate Phobias, prevent relapses as well as help build self-esteem and self-confidence.

Homeopathic medicines can formulate a positive change in people suffering from these distressing states of mind and behaviour. Homeopathy can help patients by reducing their anxiety levels 
and thus make patients capable of dealing with stressful situations.

Anxiety disorders also include conditions like social phobias, agoraphobias in which patients develop phobias from society, from meeting people etc. And then they isolate themselves and when such conditions become chronic it leads to depression and suicidal disposition as they cannot function normally. There is a need to divert prevention efforts towards such patients considering the number of suicidal cases increasing each year. That is where homeopathy can help.

Homoeopathy is most certainly effective in treating cases of ANXIETY DISORDERS where the cause is known. In today's world, where there is fast life, hurry and worry people find it difficult to cope with stressful situations. These events trigger the disease in a predisposed individual. Homeopathic case taking in such patients is to be done in full detail taking into account the childhood, family environment during childhood, interpersonal relationships etc. . Whenever such cases come at a early stage to the Homoeopath, then he is able to evaluate the phase of the affecting disease after studying the number of factors and the causative factors and successfully provide the similimum, for a definite cure.

\section{Homeopathic Remedies for Anxiety}

Homeopathic remedies have been used throughout the world for thousands of years and their benefits have been repeatedly documented by holistic practitioners. Remedies of this type are frequently sought by those who suffer from anxiety disorders or chronic panic attacks. they are

\section{Aconitum napellus:}

AILMENTS FROM: Sudden fright, fear, shock.

\section{Argentum nitricum:}

This remedy can be helpful when anxiety develops before a big event: an exam, an important interview, a public appearance or social engagement.

3.Arsenicum album: The anxiety that is found in Ars. is intermingled with fear, with impulses, with suicidal inclinations, with sudden freaks and with mania. The anxiety takes form also in the rest- lessness, in which he constantly moves. If he is able to get up he goes chair to chair.

\section{Aurum-Met:}

Such a patient shows an overly conscientious, work oriented attitude and an easily agitated conscience. There is also an obsession with certain ideas that cannot be easily shaken such as the feeling of being deserted by one's best friends or the suicidal impulse to put an end to this worthless life.

\section{Calcarea carbonica:}

This remedy is usually indicated for dependable, solid people who become overwhelmed from physical illness or too much work and start to fear a breakdown. Their thoughts can be muddled and confused when tired, which adds to the anxiety. Frightened, apprehensive mood, as if some misfortune were about to happen to him, or someone else, which he could in no way overcome. Worry and bad news may agitate them, and a nagging dread of disaster (to themselves or others) may develop. Fear of heights and claustrophobia are also common. A person who needs this remedy is often chilly and sluggish, has a craving for sweets, and is easily fatigued.

\section{Carcinosin :}

Fastidious in his work; Desire to come for appointment on time. Fears to make mistakes. Tendency to adapt too much to the requirements of others to get their approval. Excessive sense of duty and hence workaholic.

\section{Gelsemium:}

Feelings of weakness, trembling, and mental dullness (being "paralyzed by fear") suggest a need for this remedy. It is often helpful when a person has stage-fright about a public performance or interview for children and young people, especially women of a nervous, hysterical temperament. STAGE-FRIGHT, NERVOUS DREAD OF APPEARING IN PUBLIC THE ANTICIPATION OF ANY UNUSUAL ORDEAL, PREPARING FOR CHURCH,THEATRE, OR TO MEET AN ENGAGEMENT, BRINGS ON DIARRHOEA.

\section{Ignatia amara:}

It is one of the chief remedies for hysteria. Ner- 
vous temperament--women of sensitive, easily excited nature. Alert, nervous, apprehensive. A sensitive person who is anxious because of grief, loss, disappointment, criticism, loneliness (or any stressful emotional experience) may benefit from this remedy.

\section{Kali Arsenicum:}

Anxiety in the morning on waking, but most marked in the evening and during the night. $\mathrm{He}$ is anxious without cause, about his health; anxious before stool; wakens during the night with anxiety and fear. She is restless of mind and body, evening and night; anxious tossing all night. He fears to go to bed. He fears death, or a crowd of people, yet equally dreads being alone. Fear that something will happen. Fear of people. $\mathrm{He}$ is very easily frightened and startled. He has frightful delusions and sees images. Nervous depression. Great nervousness. Face looks frightened and anxious.

\section{Kali Brom:}

Nervous, restless; cannot sit still, must move about or keep occupied; hands and fingers in constant motion; fidgety hands; twitching of fingers. Night terrors of children; grinding teeth in sleep, screams, moans, cries; horrible dreams, cannot be comforted by friends. Suicidal mania. Much concerned about health, complains without cause. Depressive delusions; thinks he is pursued; will be poisoned; will commit some great crime, will murder her children or husband. Melancholy, much concerned about health, complains without cause. Nervous. Brain fag, from grief and anxiety.

\section{Kali Carbonicum:}

Great aversion to being alone Timid and apprehensive of future and about her disease. Fear of being alone; fears she will die. Anxiety with fear. Very easily frightened .Full of apprehension.

$\mathrm{He}$ is afraid that he might not get well. Apprehensive and anxious about her disease

\section{Kali phosphoricum:}

This is one of the greatest nerve remedy. PROSTRATION. Weak and tired. Conditions arising from WANT OF NERVE POWER, neurasthenia, mental and physical depression, are wonderfully improved by this remedy. The causes are usually excitement, overwork and worry. Anxiety, NERVOUS DREAD, lethargy.

\section{Lac caninum:}

This is for nervous, restless, highly sensitive organisms. Fears to be alone; of dying; of becoming insane; of falling down stairs. Despondent, hopeless; thinks her disease incurable .Very nervous; constant dread; a feeling as if she was going to become unconscious.

\section{Lycopodium:}

Individuals likely to respond to this remedy feel anxiety from mental stress and suffer from a lack of confidence. They can be self-conscious and feel intimidated by people they perceive as powerful (yet may also swagger or be domineering toward those with whom they feel more comfortable).

\section{Medorrhinum :}

TIME PASSES TOO SLOWLY. Is in a great hurry. Hopeless of recovery. Fears going insane. Nervous, restless. Fear in the dark and of someone behind her. In a great hurry; when doing anything is in such a hurry that she gets fatigued. Anxious; nervous and extremely sensitive; starts at the least sound. Many symptoms are worse when thinking of them. Anticipates death; always anticipating something bad.

\section{Natrum muriaticum:}

Deep emotions and a self-protective shyness can make these people seem reserved, aloof, and private. Even when feeling lonely, they tend to stay away from social situations, not knowing what to say or do. (Inhibitions sometimes leave completely if they turn to alcohol, which makes them feel embarrassed afterwards.) Easily hurt and offended, they can brood, bear grudges, dwell on unhappy feelings, and isolate themselves-refusing consolation even when they want it. However, they are often sympathetic listeners to other people's problems. Claustrophobia, anxiety at night (with fears of robbers or intruders), migraines, and insomnia are often seen when this remedy is needed. He might turn inward after grief and disappointments and may develop obsessive traits, expressed in the conscientiousness about trifles and quick annoy- 
ance at small mishaps. Tendency to develop resentment as well as remorse and self-blame.

\section{Natrum ars:}

The nervousness is revealed by their general physical restlessness. Their hands are restless, their fingers are restless, and often there is a slight twitch of their shoulder, arm, or the muscles of their face during conversation. VERY METICULOUS AND CONSCIENTIOUS.

\section{Phosphorus:}

People who need this remedy are openhearted, imaginative Anxiety about the future, irritability and anxiety, Apprehension, as if she was grieved about something, frequently recurring. Anguish, as if about to die. Restlessness during thunderstorms. Fearfulness and horror.

\section{Pulsatilla:}

People who need this remedy often express anxiety as insecurity and clinginess, with a need for constant support and comforting. The person may be moody, tearful, whiny, even emotionally childish. (Pulsatilla is a very useful remedy for children.) She is most nervous, fidgety. Tremulous anxiety, as if death were near. Anxiety, even to suicide.

\section{Silicea :}

People who need this remedy are capable and serious, yet are also nervous, shy, and subject to bouts of temporary loss of confidence. Anxiety can be extreme when they are faced with a public appearance, interview, examination, or any new job or task. Worry and overwork can bring on headaches, difficulty concentrating, and states of exhaustion, oversensitivity, and dread. Responsible and diligent, they often overreact and devote attention to tiny details - making their worries (and their work) more difficult. Marked anticipatory anxiety is an important feature of this drug.

\section{Thuja Occidentalis:}

Thuja is one of the very good remedies for generalized anxiety disorders and obsessive compulsive neurosis. The patient generally gets anxious over trifles and cannot concentrate on whatever he does. He has many fixed ideas and he finds it difficult to get rid of them. Social phobia is also commonly seen in these patients who begin to get nervous and get twitching on being approached by strangers. They are obsessively pre-occupied with issues of self-esteem, developing fixed ideas and entertaining worries about appearance, performance or health. Deep within, these patients do not feel worthy and hesitate to reveal themselves to others, fearing that they will not be liked

\section{Syphilinum:}

Syphilinum: perhaps exhibits best this compulsive neurosis. It is manifested in an obsession with cleanliness and germ-free state. There is a compulsion about checking and re-checking the correctness of former actions such as having locked the doors or switched off applications. There is a strong fear of infectious diseases and this is accompanied by constant washing of the hands. The patient is irritable to the point of violence on being opposed and impelled by a delusional tendency to feel personally exalted or superior. Syphillinum is frequently used in the homeopathic treatment of obsessive compulsive disorders, anxiety states. It's a useful drug to combat diseases that are destructive in nature and are deep-seated.

\section{Zincum-lodatum:}

They also feel that people are always checking on them. Parents, teachers or bosses are imposing all sorts of rules and are constantly keeping an eye on them. But they also have a tendency to check their own work all the time, reading and rereading their homework, learning and relearning their lessons. If they make a mistake, if they don't do their utmost to get good results they will be told to leave, there will be no place for them in this world. O standards.

\section{Review}

The below reviews are accept in above medicines are good working anxiety disorders, Dr. Vikas Sharma asked that Aconite, Arg.nit, Ars. alb of homeopathy remedies are helpful in sleeplessness in chronic anxiety patients, Dr Rajesh Shah's asked that Argentum Nitricum,Lycopodium clavatum,Silicea,Thuja Occidentalis, Syphilinum, Natrum Muriaticum are highly effective medicines in anxiety and related disorders, Jon- 
athan Davidson etal.(1997)suggested that the Homeopathy may be useful in the treatment of affective and anxiety disorders in patients with mildly to severely symptomatic conditions.

George Vithoulkas(2001)explain that the Lycopodium and Sepia, 25 most important homeopathic remedies for anxiety and jealousy are succinctly described.

D.G. Baker et al.(2003) study that the homeopathic $A$. nitricum $12 X$ does not reduce test anxiety in a general population of university students.

Pilkington et al.(2006)studied that the homeopathy is quite frequently used by people suffering from anxiety. If shown to be effective, it is possible that homeopathy may have benefits in terms of adverse effects and acceptability to patients. Consequently, further investigation is indicated.

Paolo Magnani et al.(2011)results that the provides evidence that $\mathrm{G}$. sempervirens acts on the emotional reactivity of mice, and that its anxiolytic-like effects are apparent, with a non-linear relationship, even at high dilutions.

Kushingi bhanushali(2011)studied that the Homeopathy can help patients by reducing their anxiety levels and thus make patients capable of dealing with stressful situations.

Suvarna(2011)explained that the commonly indicated homeo remedies are good result in anxiety problems.

Lakshmipathy Prabhu R(2012) showed that the an anxiolytic effect of homeopathic preparation of Pulsatilla nigricans comparable to that found with a standard drug.

Reichenberg-Ullman(2012) asked that Homeo-pathy results in increased self-perception and deeper insight which enables ther- apy to progress far more rapidly and effectively. These remarkable medicines seem to break the "resistance" to therapy. Homeopathic treatment removes depression, anxiety, delusions, dissociation and other symptoms so that therapy can do what it really does best: promote growth and development through self knowledge.

Mandana Bagherian (2014)studied that the homeopathic therapy can be used as an effective method to treat anxiety and depression disor- ders.

\section{Conclusion}

The review article comprehensive search for published and unpublished studies has demonstrated that the evidence for the effectiveness of homeopathy in anxiety and anxiety disorders is limited. A number of studies of homeopathy in a range of conditions were located but the randomised controlled trials report contradictory results are underpowered or provide insufficient details of methodology \& conclusions on the effectiveness of homeopathy for anxiety. However it appears that homeopathy is quite frequently used by people suffering from anxiety. If effective it would have benefits in terms of adverse effects, acceptability to patients and possibly cost.

\section{References}

D.G. Baker,S.P Myers,I Howden,L Brooks(2003) The effects of homeopathic Argentum nitricum on test anxiety,complementarytherapiesinmedicine, Volume 11, Issue 2, Pages 65-71.

George Vithoulkas(2001) Classical homeopathy for anxiety and jealousy, Zurich.

Jonathan Davidson, R M Morrison, J Shore, G Bedayn(1997) Homeopathic treatment of depression and anxiety, Alternative therapies in health and medicine 3(1):46-9 .

Kushingi bhanushali(2011) SCOPE OF HOMOEOPATHY IN THE TREATMENT OF ANXIETY DISORDERS, HAHNEMANN COLLEGE OF HOMEOPATHY, LONDON.

Lakshmipathy Prabhu $\mathrm{R}^{1}$, Ruckmani A, Venkatesan D, Madhusudhanan N, Pavithra R.(2012) Anxiolytic effect of homeopathic preparation of Pulsatilla nigricans in Swiss albino mice, Homeopathy., 171-4.

Mandana Bagherian*, Adis Keraskian Mojembari and Mohammad Hakami(2014) The Effects of Homeopathic Medicines on Reducing the Symptoms of Anxiety and Depression, Journal of Traditional Medicine \& Clinical Naturopathy.

Paolo Magnani, Anita Conforti, Elisabetta Zanolin, Marta Marzotto (2011)effect study of Gelsemium sempervirens in high dilutions on anxiety-related responses in mice, Evid Based Complement Alternat Med.

K. Pilkington,G. Kirkwood,H. Rampes,P. Fisher,J. Richardson(2006)disorders: a systematic review of the research. Homeopathy ; 95(3): 151-162 
Dr Rajesh Shah's, Homeopathy Medicines for Anxiety Disorders, www.askdrshah.com.

Reichenberg-Ullman(2012) The Homeopathic Treatment of Depression and Anxiety, Narayana verlag, Germany. b9574.

Suvarna(2011) Anxiety and Homoeopathic Remedies, Homeopathic Journal :: Volume: 4, Issue: 10,

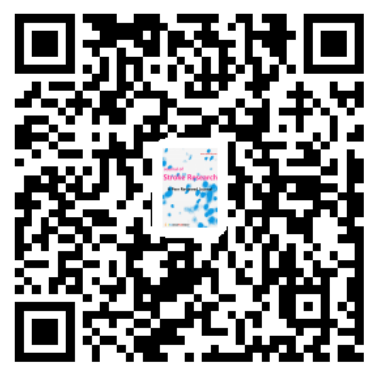

